\title{
Alchemilla Vulgaris Extract as Green Inhibitor of Copper Corrosion in Hydrochloric Acid
}

\author{
Rasha Khalid Ahmed ${ }^{1,2}$, Shengtao Zhang ${ }^{1, *}$ \\ ${ }^{1}$ School of Chemistry and Chemical Engineering, Chongqing University, China \\ ${ }^{2}$ Department of Chemical Engineering - College of Engineering - University of Tikrit, Iraq \\ *E-mail: stzhangcqu@163.com.stzhang@cqu.edu.cn.
}

doi: $10.20964 / 2019.11 .43$

Received: 7 July 2019 / Accepted: 28 August 2019 / Published: 7 October 2019

\begin{abstract}
This paper aims to assess the anti-corrosion capability of Alchemilla Vulgaris (ALV) extract in $1 \mathrm{M} \mathrm{HCl}$ on pure copper with the perspective of exploring and developing an eco-friendly or natural corrosion inhibitor. Therefore, in the current study, the extraction of ALV was made from its leaves and its anticorrosion potential was studied by utilizing weight loss experiment, potentiodynamic polarization test, scanning electron microscopy (SEM) analysis and electrochemical impedance spectroscopy (EIS). It has been found that in $1 \mathrm{M} \mathrm{HCl}$ solution, the ALV was effectively inhibited the corrosion on pure copper metal. The results obtained from the electrochemical tests and weight loss way proved that the anti-corrosion capability of ALV was increased with increasing its concentration. Inhibition is achieved through the adsorption of Alchemilla molecules onto the pure copper surface by adopting the Langmuir adsorption isotherm model. SEM study also indicates that the inhibitor gave positive results when adsorption on the surface of copper. This study directs attention to highly inhibitive properties of some natural compounds as the ALV extract. Hence, it is considered the first time to investigate the efficiency of ALV extract as a potential pure copper corrosion inhibitor in a $1 \mathrm{M} \mathrm{HCl}$ solution. The anti-corrosion effect of ALV extract has been proven by standard methods. The findings of this research are important because ALV, as a natural inhibitor material, could find use in industries where pure $\mathrm{Cu}$ is used.
\end{abstract}

Keywords: Copper, Corrosion inhibitors, ALV extract, Eco-friendly, Hydrochloric acid.

\section{$\underline{\text { FULL TEXT }}$}

(C) 2019 The Authors. Published by ESG (www.electrochemsci.org). This article is an open access article distributed under the terms and conditions of the Creative Commons Attribution license (http://creativecommons.org/licenses/by/4.0/). 